\title{
Catalina todos los Jueves ${ }^{1}$
}

\author{
Alejandro José López²
}

$\mathrm{D}$ espués de lo ocurrido el jueves de la semana pasada, hoy está siendo un día especialmente malo para Catalina. Trata de concentrarse. Cuatro dientes de ajo en el mortero (bam-bacatam), una pizca de sal y pimienta al gusto, bien mezclados (tracatamtan-plas). Imposible: se había acostumbrado tanto al ruido de la batería, que este silencio largo y tedioso se le parece demasiado al infierno. Ahora, la mantequilla sobre la paila de teflón, a fuego lento, para que no se arrebate; luego, la cebolla picada con el tomate, como le gusta a él (como le gustaba, bacatam, maldita sea, tendrá que habituarse de nuevo a conjugar en pasado). Catalina no puede evitar que el silencio le humedezca la mirada, pero sí va a omitir su nombre en cada pensamiento. El Baterista, en la memoria será el Baterista a secas y así elude uno cualquier trato cariñoso; al fin y al cabo, no se lo merece.

Había aparecido desgreñado y con ganas de comprarse un redoblante nuevo, de los electrónicos que son carísimos; claro que eso lo averiguó ella después. La invitación había sido idea de Esperanza, una vieja amiga del colegio que estaba muy emocionada porque dizque el concierto iba a ser regio; además,

${ }^{1}$ Tomado de López, A. (2005). Dali violeta, cuentos. Cali: Fundación Literaria Botella y Luna.

${ }^{2}$ Alejandro José López. Doctor en literatura y medios de comunicación por la Universidad Complutense de Madrid, actualmente se desempeña como Profesor Asociado en la Universidad del Valle. Ha publicado dos libros de ensayos: Entre la pluma y la pantalla (2003) y Pasión crítica (2010), dos de crónicas y entrevistas: Tierra posible (1999) y Al pie de la letra (2007), dos de cuentos: Dalí violeta (2005) y Catalina todos los jueves (2012), y una novela: Nadie es eterno (2012). Cuentos y ensayos suyos han sido publicados en diversas antologías y revistas internacionales, y han sido traducidos al alemán y al francés. Entre los años 2004 y 2008 dirigió la Escuela de Estudios Literarios perteneciente a la Universidad del Valle. 
los músicos son unos churros, ¡cómo se te ocurre que no vas a ir! Pero yo no conozco a nadie; y la verdad, el rock no es que me mate. ¡Pendeja!, ¿y vos creés que a mí sí? Al menos vos sos más lanzada... No me vengás con ésas, que yo me sé bien tus mañas. Y Catalina decidió ir. Y se dio sus mañas. Tanto que, durante las semanas siguientes a la presentación, su apartamento y sus costumbres se transformaron notoriamente. Lo primero fueron los cuadros. No más bodegones bucólicos; en adelante, afiches de The Beatles (al principio se ven anacrónicos, pero después uno se familiariza). Luego, el aspecto personal. Nada de rulos y mascarillas antes de acostarse; ahora, pijamas rojas de satín suelto (con luz tenue son de gran ayuda). Y para completar, la cocina. Adiós a la comida criolla; en lo sucesivo, pizzas y hamburguesas (con todo y su fisonomía aborigen, en lo gastronómico tiene el Baterista aspiraciones cosmopolitas. Está bien: tenía, tracatamtan, habrá que adaptarse). Por eso es que hoy Catalina ha vuelto a su vieja rutina: fríjoles con ogao, como había correspondido siempre al menú de los jueves.

Antes de poner la olla, abre la bolsa, separa una semilla y la siembra en el matero de al lado. A la postre, piensa, el amor tiene esa misma condición. El asunto es aguardar el momento oportuno: un poco de tierra, los cuidados necesarios, la magia de la humedad; entonces, la pepita de fríjol, después de haber permanecido almacenada durante meses, revela de pronto sus ansias de brotar. Quizás el apretón de la tierra se parezca a una caricia y el riego a una lubricación erótica; tal vez la germinación sea otra forma del orgasmo. Punto. Ya no más, Catalina; mejor que regresés a los menesteres culinarios. Observa los utensilios sucios, dispersos sobre el mesón, y decide organizarlos. Abre la llave del lavaplatos: el agua está fría. Comienza a sobar la esponja sobre la tabla de picar, con furia, y la espuma se desborda. Seguidamente, al chorro. Así está perfecto: todo limpio, como debe ser.

Aún no termina con los trastos y la ausencia vuelve a hacer de las suyas en el alma de Catalina. Estriega las cucharas, pero 
su mente se niega al silencio (turulumtun). Continúa con los dos tazones de mezclar salsas (tumtun-tan). Por fin, el cuchillo (iplas!, tenía que ser, sólo hace falta un medio descuido y ya está). Catalina se lleva el dedo a la boca y lo succiona con fuerza, casi con avidez. Comprueba que la rabia y la sangre saben a lo mismo. Otra vez pone la mano bajo el chorro: apenas se asoma lo rojo por la herida, ahí mismo lo barre la fuerza del agua. Así es todo en la vida, eso se sabe; sin embargo, mientras pasa el dolor, si sentís que el llanto te desborda, es mejor no contenerse. Catalina se abandona al capricho de sus ojos. Hubiera querido que las cosas fueran de otra manera, pero es claro que ya no hay nada que hacer. Vuelve a chuparse el índice: maldito Baterista, el filo de la ausencia hiere más hondo todavía.

Desde el comienzo, ambos sabían que la cuenta sería regresiva, como una bomba de tiempo. No hablaban de ello porque nadie quiere abordar temas dolorosos mientras haya posibilidad de esquivarlos; pero, sobre todo, porque cada uno decidió dar por hecho que el otro aprobaba sus razones. Sentían que era mejor así. A él le gustaba pensar que Catalina estaba de acuerdo en recibir sexo como pago por favores y atenciones (tictac-tic-tac); a ella, que el Baterista también pensaba en el amor como algo a lo cual se accede a través de méritos. A Catalina le encantaba suponer que él soñaba con el amor eterno (tactic-tac-tic); al Baterista, que ella comprendía perfectamente la diferencia entre amor y sexo. Había otra cosa igualmente inconfesada pero en la cual sí coincidían plenamente: los dos sospechaban que la detonación final ocurriría durante el próximo cumpleaños de él (jboom!).

En este nuevo affaire, Catalina había tenido que variar sus tácticas. Lo de regalar lociones y ropa fina quedó en el pasado, pero esto no favoreció su economía. Cada fin de mes, para celebrar uno más de haber conocido al Baterista, sobrevenía 
la compra de cencerros, afiches, cigarrillos importados, baquetas, zarcillos y un montón de cachivaches. Por su parte, el huésped, cuando no se aplicaba a los drums (tracatamtan-plas), dormitaba. Y hasta se diría que pasaba feliz en la casa, de no ser por una labor inexcusable: sus deberes de consorte. Ahí las cosas se ponían un poco tensas, porque quién puede concentrarse en algo con este dolor de cabeza. Pero yo tengo mucho frío y vos no ponés de tu parte. Es que no es un problema de voluntad, ¿no me ves como estoy de enfermo? Entonces, Catalina empezaba su lloriqueo y el rockero comprendía que no tenía escapatoria. Así que sacaba de su bolsillo un moño chiroso de la Sierra Nevada, armaba con él un pitillo y, al cabo de unas cuantas lumbres (suip-suip-suip), ya se sentía dispuesto para la pasión. Con todo, aún le faltaba sortear lo peor: la máxima agitación de ella y sus alaridos estrepitosos. El Baterista cerraba los ojos y se esforzaba en imaginar un tren maravilloso descendiendo desde el cielo por sus rieles multicolores y trayendo, sonriente, a un ángel guardián: John Lennon. Son pocas las fantasías que logran salvar del asco a un pobre desgraciado.

Hasta que por fin llegó su cumpleaños, precisamente el jueves de la semana pasada (tic-tac-tic-tac). Aunque la suerte estaba echada, Catalina hizo un último intento. Compró papel brillante y fabricó una envoltura preciosa, capaz de fascinar al más indolente. La tarjeta había sido timbrada, por encargo suyo, con una foto del cuarteto mágico durante el último concierto en Liverpool. Para rematar, un moño psicodélico que ella tejió con sus propias manos ceñía el paquete de previsible redondez. Y vino el momento (tac-tic-tac-tic). Mientras el Baterista apagaba las velas de la torta, ella abrigó alguna esperanza; sin embargo, tan pronto como destapó su redoblante nuevo, él la miró a los ojos y todo estuvo claro: había en su gesto tal mezcla de repugnancia, lástima y gratitud, que esta vez fue Catalina quien reclamó la marihuana para facilitar las cosas (suip-suip-suip). El rockero le hizo el amor y, cuando se disponía a marcharse, ella partió el pastel de chocolate que había decorado con tanto 
esmero y lo sirvió. Él comió y luego pasó lo que tenía que pasar (;boom!).

Ahora, ella no tiene más remedio que cocinar para sí misma, lo cual revela su arribo a la cúspide del desamparo. Abre la alacena buscando especias y se descubre reflejada en el vidrio de la puerta. Una lágrima le desdibuja su imagen. Quisiera ver una simple hortelana, febril plantadora de fríjoles; pero lo que allí aparece, entre nudos y ardides culinarios, es un rostro de araña suspirando por la ausencia de otro moscardón malogrado. Necesita superar este despecho ocioso. Busca con urgencia un hilillo de entretención para saltar desde su hastío y conseguir un poco de sosiego. Se dirige entonces al patio para trasplantar los retoños del matero. Remueve la tierra y hace un nuevo surco en el pequeño huerto que allí cultiva. De pronto, algo interrumpe su laboriosidad: desde la calle se ha colado el sonido de una campanilla redentora (jtin-tilín-tilín!). Catalina corre hacia la ventana de la fachada y se asoma. Afuera hay un hombre, moreno y colosal, conduciendo una carreta de mano que rebosa de frutas tropicales. Ella lo llama y sale rápidamente para averiguar calidades y precios.

Salvo algunas magulladuras menores, cada fruta está intacta. El negro parece amable y lo confirma cuando le alcanza un mango maduro, pero remata el ofrecimiento con una sonrisa desdentada y ella se decepciona. Mientras baja la mirada, advierte la figura corpulenta del frutero y recobra el entusiasmo. Nada es perfecto en este mundo, piensa; así que más vale corresponder el gesto afable del hombre con la dulzura de su conversación. Ensaya un abanico de temas que alterna involuntariamente con suaves mordiscos a su índice: de los precios del mercado a la corrupción política (él asiente con la cabeza, sin comprender mayor cosa), del aburrimiento cotidiano a este solazo que está haciendo (él se pasa la mano por 
su frente sudorosa, ;zluish!, para corroborar lo que escucha), de la inseguridad del país a las inclemencias de la soledad (acaba de notar que a ella le ha ocurrido algo en el dedo y se acerca para observárselo detalladamente). Catalina interrumpe su perorata: es que me corté.

El hombre permanece silencioso. Al volver sus ojos hacia la carreta, ella se percata de que las frutas están perfectamente clasificadas y de que sobre cada especie hay un letrero de cartón, burdamente cortado, indicando el precio por libra. Él toma una bolsa plástica del paquete que se halla en la esquina de los manubrios y ella aprovecha el instante para inspeccionarlo de pies a cabeza. Su rostro luce bien afeitado y, pese a la cantidad de sudor que lo recorre, sus rasgos se ven tan finos que un poco mejor vestido podría resultar simpático. Cuando se dispone a ofrecer lo que vende, el negro inicia una danza de movimientos que oscilan entre la brusquedad y el esmero, la rudeza y la precisión. Catalina se sorprende. No puede hablar, piensa; o sea que ha de tener una fuerza descomunal, como todos los mudos. Decide acercársele con el pretexto de mirar las frutas y así, sin querer ( $z$ zluish!), le toca el brazo emparamado, cobrizo, fornido. Ahora, se mira la palma de su mano, que ha quedado mojada, cerciorándose de que él lo advierta. Lo que pasa es que hace rato preparó un jugo de tamarindo delicioso y lo puso en la nevera: debe de estar helado (ella hace señas, como puede, con su pulgar, orientándolo hacia su boca, subiendo y bajando el codo). ¿La puede oír? El hombre asiente con la cabeza. Perfecto. Tal vez quiera beber un poco y refrescarse. Él vuelve a sonreír, amablemente (ella hubiera preferido que manifestara su agrado de otra forma; pero, bueno, qué se le va a hacer).

Catalina se dispone a subir por un vaso de jugo, pero acaba de ocurrírsele algo mejor (jtin-tilín-tilín!). Sí: sucede que tenía un invitado a almorzar y, claro, ella cocinó un almuerzo delicioso (fríjoles con ogao). Todo iba muy bien hasta que, hace un momento, la llamaron para cancelarle la cita. Y la verdad es que ha sido una mala noticia, porque a nadie le gusta comer 
solo; a mí por lo menos ésa es una de las cosas que más me chocan en la vida, ¿a usted no? En fin, pensándolo bien, no es que todo esté perdido, porque si le parece, quizás, podría ser... El frutero se sorprende con la insinuación, pero la considera muy seriamente. Observa a la señora: se ve ilustre, sobre todo por el collar de oro que luce en su cuello; sin embargo, hay un problema. El negro vuelve la mirada sobre su carreta y Catalina se adelanta a la objeción, porque bien pueden almorzar con la ventana abierta y así cuidan perfectamente las frutas. Él está de acuerdo y sigue, tras ella, por el zaguán. Mientras va entrando, en la espalda del hombre se nota, a la altura del cuadril, la cacha de un cuchillo que sobresale de su envaine.

\section{4}

Han pasado tres meses desde su primer almuerzo juntos y el frutero ya comprende la mecánica del trueque. El hecho es que cada jueves consigue buena comida sin los tropiezos de otros días. Y ha recibido más beneficios. Cuando se cumplió el primer mes, Catalina le regaló un transistor portátil que ahora lo distrae cotidianamente en sus recorridos; cuando completaron el segundo, le dio un reloj de pulso que él ha estado a punto de empeñar en varias ocasiones (tic-tac-tic-tac). Hoy se celebra el tercero y ella está organizando la mesa para servir los fríjoles con ogao; pero está de mal humor porque acaba de confirmar una sospecha: sus cubiertos de plata, los del juego que sólo utiliza en ocasiones especiales, están incompletos (tac-tic-tactic). Necesita tranquilizarse y para ello se dedica a regar el matero de la cocina. Después decide, aprovechando que aún no llega su invitado, preparar uno de esos pasteles de chocolate que tanto le gusta decorar.

A las doce en punto se escucha la campanilla (jtin-tilintilín!). Catalina abre la puerta y el negro entra con una piña entre sus manos. Trae además una gran expectativa porque sabe perfectamente que hoy es día de celebración. Con todo, durante 
los últimos jueves, la impaciencia le ha estado inundando el ánimo (al principio sentía como una filtración de agua que anegaba de a poco el pequeño bote de su corazón: click... click... click...; pero con el transcurrir de las semanas, al no haberse corregido el defecto oportunamente, ya la pequeña embarcación está por naufragar). Sí: la señora no pone de su parte para mejorar las cosas y se ha empeñado en mantener demasiado lento el cuentagotas de las dádivas (click... click... click...). Y todo está a punto de empeorar. Al llegar a la mesa, luego de haber saludado, el frutero se sobrecoge: encima del comedor no hay más que platos. Ni paquete, ni caja, ni envoltorio, ni nada. Ella guarda silencio durante el almuerzo. Sabe que es mejor así. Desde el comienzo ha percibido la respiración agitada del comensal y, antes de que la ofuscación lo desborde, se apresura a servirle el postre. En efecto, apenas termina de comerse los fríjoles, él prosigue a devorar la torta con su acostumbrada inelegancia. Se saborea. Mientras lo hace, examina el entorno una vez más, tratando de no resultar evidente. Hay demasiadas cosas que lo estimulan: candelabros de bronce, cubiertos de plata, porcelanas chinas, pequeños electrodomésticos.

Ella se pone de pie, recoge la loza y se dirige hacia el lavaplatos. Sin atreverse aún a pronunciar palabra, se da al oficio de la limpieza. Abre la llave y sus manos tiemblan al contacto con el agua fría. Evita coger los cubiertos: no querría ningún accidente ahora (tic-tac-tic-tac). El negro entra a la cocina. Para pelar la fruta que ha traído, desenvaina su cuchillo. Luego se dispone a trozar la piña en rebanadas; pero no logra concentrarse en su labor porque, cada que levanta su mirada hacia la señora, el collar de oro captura su atención (tac-tictac-tic). Catalina siente que transita por el borde de un abismo; así que decide buscar seguridad, serenar la estancia. Entonces, sigilosa, cariñosamente, se acerca al frutero y, con el revés de su mano, le acaricia el rostro. Pero el hombre desata su furia y reacciona dándole un estrujón violento. A pesar de que un escalofrío le recorre el cuerpo, en un primer momento ella trata 
de no perder los estribos; sin embargo, tan pronto se percata de que el filo del cuchillo apunta en su dirección, no tiene más remedio que emprender la huida.

Va hacia el comedor y el negro corre tras ella, derrumbando a su paso porcelanas, candelabros y el matero de los fríjoles (¡trash-cluinc-sploom!). Antes de que pueda alcanzarla, ambos han dado varias vueltas en torno a la mesa (él sin evitar los destrozos y ella sin contener los gritos). Catalina trata de encontrar las palabras adecuadas para tranquilizarlo, porque si lo que quiere son las cosas de valor, nadie tiene por qué salir lastimado; en serio: puede llevarse lo que quiera, pero guarde ese cuchillo. Él responde con un tajo al aire, por encima de la mesa, que casi logra alcanzarle el pecho. Entonces, repentinamente, el frutero se detiene y se lleva las dos manos al estómago (en medio del ardor que siente en las entrañas, comienza a ver, enfrente suyo, grandes manchas oscuras que van creciendo y se van juntando hasta convertir el mundo entero en una gran mancha negra). La suerte está echada, piensa Catalina. No se había equivocado en sus pronósticos. Por fin, pasa lo que tiene que pasar: el hombre colosal se desploma sobre el comedor (¡trash-cluinc-sploom!).

$\mathrm{Al}$ final de la tarde, Catalina está todavía en el patio. Acaba de terminar su labor allí. Un nuevo promontorio de tierra está removido y listo para la siembra, así que hoy se siente más hortelana que nunca. Tendrá que conseguir otro matero para usarlo como almáciga, piensa. Está exhausta luego de tanto trabajo y se pasa la mano por su frente sudorosa (jzluish!). De pronto, desde el fondo de la casa, un nuevo sonido la reclama (rinrin-rin). Ojalá sea Esperanza con alguna de sus proposiciones raras (la verdad es que está necesitando urgentemente un poco de diversión). Catalina corre a contestar $\mathrm{y}$, antes de ponerse al auricular, se para por un instante a observar en lo que ha 
quedado convertida su mesa. Pensándolo mejor, si se trata de alguna invitación va a tener que desecharla porque aún tiene mucho oficio por hacer. Incluso, cuando acabe con el aseo, lo más indicado sería irse de compras para reponer los trastos rotos (rin-rin-rin); en fin: ¿aló? 